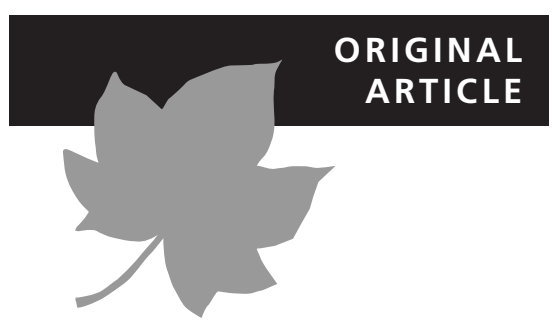

\title{
Social calls are subject to stabilizing selection in insular bats
}

\author{
Danilo Russo $^{1,2 \star}$, Sérgio Teixeira ${ }^{3}$, Luca Cistrone ${ }^{4}$, José Jesus ${ }^{3,5}$, \\ David Teixeira ${ }^{3}$, Tamira Freitas ${ }^{3}$ and Gareth Jones ${ }^{2}$
}

${ }^{1}$ Laboratorio di Ecologia Applicata,

Dipartimento Ar.Bo.Pa.Ve., Facoltà di Agraria, Università degli Studi di Napoli Federico II, Portici (Napoli), Italy, ${ }^{2}$ School of Biological Sciences, University of Bristol, Bristol, UK, ${ }^{3}$ Department of Biology, University of Madeira, Campus da Penteada, Funchal, Portugal, ${ }^{4}$ Forestry and Conservation, Via Botticelli, Cassino (Frosinone), Italy and ${ }^{5}$ Faculty of Sciences, Centre for Environmental Biology, University of Lisbon, Lisbon, Portugal

${ }^{\star}$ Correspondence: Danilo Russo, Laboratorio di Ecologia Applicata, Dipartimento Ar.Bo.Pa.Ve., Facoltà di Agraria, Università degli Studi di Napoli Federico II, via Università 100, I-80055 Portici (Napoli), Italy.

E-mail: danrusso@unina.it

\section{ABSTRACT}

Aim Bats communicate by emitting social calls, and these often elicit reactions in conspecifics. Many such vocalizations are species-specific so that unambiguous signals can be transmitted and interpreted by conspecifics. In species-rich assemblages, evolutionary pressures might prompt interspecific diversification of call structure so that communication with heterospecifics is avoided. In speciespoor island communities, where no risk of miscommunication occurs, stabilizing selection should prevail and preserve call structure and function. Call structure in island bats might be inherited from colonizers from the mainland and be maintained with little change in the absence of selection from heterospecifics. To test this hypothesis we studied Pipistrellus maderensis, an insular taxon occurring on the Madeira Archipelago, the Canary Islands and the Azores. It is closely related to one of the most widespread European pipistrelles, Pipistrellus kuhlii. Pipistrellus maderensis most probably evolved from a common ancestor shared with $P$. kuhlii, or from founders of that taxon that colonized the islands. We hypothesized that on Madeira Island, where no risk of ambiguous communication with heterospecifics exists, the structure and function of social calls should have been preserved by stabilizing selection. Echolocation calls, subject to different selection pressures, may instead show more pronounced differences between P. maderensis and P. kuhlii.

Location Madeira Island (Portugal, Atlantic Ocean), central and southern Italy.

Methods We recorded social and echolocation calls from allopatric populations of the two pipistrelles and explored interspecific differences in time and frequency characteristics. We also conducted playback experiments by broadcasting recordings of social calls from $P$. kuhlii and P. maderensis (taken respectively in peninsular Italy and on Madeira) and monitoring the bats' responses.

Results Social call structure showed a strong similarity between species, whereas echolocation calls were markedly different and exhibited a mean divergence of over $6 \mathrm{kHz}$ in their frequency of maximum energy. On Madeira, P. maderensis significantly reduced flight activity when we broadcast $P$. kuhlii signals, as did $P$. kuhlii in Italy in response to $P$. maderensis calls.

Main conclusions Reliable interpretation of social calls provides benefits to both the signaller and the receiver because signals help to optimize food exploitation at foraging sites. In the absence of closely related species that can emit similar calls, this advantage may have acted as a strong evolutionary pressure, stabilizing social call structure in $P$. maderensis in insular ecosystems with limited foraging resources.

\section{Keywords}

Allopatry, bioacoustics, communication, echolocation, evolution, island evolution, Italy, Madeira, Pipistrellus kuhlii, Pipistrellus maderensis. 


\section{INTRODUCTION}

Specialized selective forces associated with island environments prompt the appearance of new characters that may differ markedly from those found in the ancestral colonizers (Mayr, 1967). An analysis of changes in the morphology of mammals demonstrated that islands may in fact accelerate evolutionary processes, promoting faster diversification (Millien, 2006). However, in the absence of fitness-dependent environmental or ecological change, traits that prove crucial for individual fitness will be preserved in their original states by stabilizing selection, a form of natural selection that eliminates the extremes of a character and favours intermediates (Stearns \& Hoekstra, 2005). Stabilizing selection is therefore a key process in maintaining character stasis over prolonged periods (Estes \& Arnold, 2007).

The structure of communication signals in animals may be stabilized whenever divergence from average signal properties results in decreased effectiveness of information transfer. Stability of signals allows for the fine-tuning between signaller and receiver that is necessary for mutual recognition and unambiguous communication (Ritchie, 1996). For example, signals that convey species identity for mate recognition can be maintained by stabilizing selection exerted by receivers to decrease the risk of attracting individuals from other species (e.g. Paterson, 1985; Ryan \& Rand, 1993; Greenfield, 1997). In certain cases it can happen that only some variables of the signal are stabilized, while others are subject to different forms of selection (e.g., flash rate and length in fireflies, which evolved by directional and stabilizing selection, respectively; Greenfield, 1997). Many acoustic signals are subject to stabilizing selection, especially those involved in mate recognition (e.g. Gerhardt \& Huber, 2002; Hunt et al., 2007). Moreover, stabilization may be equally important for other forms of acoustic signalling, and here too structural divergence can be selected against so that communication is effective.

In addition to producing echolocation pulses, many echolocating bats broadcast a range of social calls exclusively for communication (Fenton, 1977, 1985, 2003; Russ et al., 1998; Pfalzer \& Kusch, 2003). Echolocation and social calls exhibit different degrees of intraspecific variation. In fact, the structure of echolocation calls is flexible, and is modified by bats in flight to optimize performance in tasks such as target detection, localization and classification in different habitats (Obrist, 1995; Vaughan et al., 1997; Russo \& Jones, 2002; Berger-Tal et al., 2007). To ensure unambiguous communication, social calls with different functions often differ in structure (Fenton, 1985), each strucutre being highly stereotyped within species. Moreover, signals having the same function in different species typically differ among species so that undesired communication with individuals from other species is avoided. Such differences are maintained even among closely related taxa (Barlow \& Jones, 1997a,b). Stereotyped social calls result from the suppression by stabilizing selection of random divergence from a species-specific signal structure that is clearly recognizable and interpretable.
In this study we hypothesize that the structure and function of frequently used social calls persist as a result of stabilizing selection in newly founded insular populations provided that no overlap occurs with calls of other island species. Indeed, calls may even be inherited in the same form by a newly evolved insular taxon deriving from the original colonizers. Stabilizing evolutionary pressures may preserve features of key signals, 'protecting' them against drift effects. The presence of species emitting similar calls might counter this process by promoting divergence from the original signal structure, thereby minimizing communication overlap between species and maintaining 'private communication channels' (Kingston et al., 2001; Thabah et al., 2006; Russo et al., 2007). This phenomenon has been described for several taxa, including orthopteran insects (Higgins \& Waugaman, 2004; HondaSumi, 2005), frogs (Höbel \& Gerhardt, 2003; Pröhl et al., 2006), birds (Irwin et al., 2001; de Kort et al., 2002) and, more recently, nocturnal primates (Braune et al., 2008).

However, such pressures appear less likely to occur on islands than in mainland regions since islands harbour fewer species (as pointed out for bats by Findley, 1993). In the absence of these selective forces, call structure is presumably stabilized by natural selection.

To test our hypothesis we selected an insular bat, Pipistrellus maderensis (Dobson, 1878). Like other pipistrelle bats (Barlow \& Jones, 1997a,b; Russo \& Jones, 1999), P. maderensis emits social calls that contain multiple components when foraging. Social calls are emitted more frequently at lower ambient temperatures or later at night (D. Russo \& S. Teixeira, pers. obs.), when reduced prey density increases competition for insect prey (Barlow \& Jones, 1997b). As in other pipistrelle bats (Barlow \& Jones, 1997b), these signals presumably function to repel conspecifics at foraging sites, given that they are often emitted during the pursuit of conspecifics. Pipistrellus maderensis is a strongly sedentary bat (Hutterer et al., 2005), and is endemic to Madeira, the Canary Islands (but see Simmons, 2005) and possibly the Azores (Rainho et al., 2002). It probably evolved from its closest relative Pipistrellus kuhlii (Kuhl, 1817) (Pestano et al., 2003), a Western Palaearctic and Afrotropical bat that is widespread in much of southern Europe (Vernier \& Bogdanowicz, 1999), or from ancestral forms common to both lineages. Ongoing work on local $P$. maderensis populations suggests that, assuming a molecular clock for cytochrome $b$ of $c$. $4 \%$ divergence per million years $\left(\mathrm{Myr}^{-1}\right)$ (as employed for other Pipistrellus species; Hulva et al., 2004), P. maderensis may have diverged from P. kuhlii c. 1.2 Ma (J. Jesus, unpublished data).

Pipistrellus kuhlii also emits social calls at foraging sites (Russo \& Jones, 1999). Barlow \& Jones (1997b) established that pipistrelle social calls are structurally and functionally species-specific; that is, they differ between species and do not elicit heterospecific reactions. Such calls may have evolved because they offer advantages both for the signaller and for the receiver. The call works to the advantage of the signaller because, by calling, the signaller repels newcomers and decreases competition for food (Barlow \& Jones, 1997b). 
Hearing the calls is advantageous for the receiver too, because it is warned that other conspecifics are already depleting the foraging patch and hence it may decide to feed elsewhere. These social calls are likely to be especially important in insular habitats, where, compared with the mainland, key selective pressures are more closely associated with intraspecific competition for limited resources (Lomolino, 2005).

Assuming that any divergence from the original social call structure would result in decreased communication performance (and, in turn, in decreased individual fitness) in P. maderensis, social calls may have been retained in their original form (presumably similar to those of P. kuhlii) by stabilizing selection.

We made the following predictions: (1) social call structure will be very similar between P. maderensis and P. kuhlii; (2) social calls may elicit heterospecific responses; and (3) echolocation calls, not being subject to the same conservative evolutionary pressures, will exhibit more pronounced divergence or variation.

\section{MATERIALS AND METHODS}

\section{Structure of social and echolocation calls}

We recorded social and echolocation calls from $P$. maderensis at foraging sites on the island of Madeira, Portugal $\left(32^{\circ} 44^{\prime} \mathrm{N}\right.$, $16^{\circ} 58^{\prime} \mathrm{W}$ ) and from P. kuhlii in three regions of central and southern Italy (Umbria, $43^{\circ} 12^{\prime} \mathrm{N}, 12^{\circ} 04^{\prime} \mathrm{E}$; Abruzzo, $41^{\circ} 44^{\prime} \mathrm{N}, 12^{\circ} 02^{\prime} \mathrm{E}$; and Lazio, $41^{\circ} 37^{\prime} \mathrm{N}, 13^{\circ} 50^{\prime} \mathrm{E}$ and $\left.41^{\circ} 29^{\prime} \mathrm{N}, 13^{\circ} 54^{\prime} \mathrm{E}\right)$. In all areas, foraging sites were very similar (street lamps close to trees), and generally at least two bats were observed foraging (i.e. recording situations were similar). Species identity could be ascertained unambiguously. Of the three bats known to occur currently on Madeira (Jesus et al., in press) - P. maderensis, Plecotus austriacus (J. Fischer, 1929) and Nyctalus leisleri (Kuhl, 1817) - only the former produces social calls of the type studied. Social calls emitted by P. kuhlii are also easily distinguished from those of other sympatric pipistrelle bats (Russo \& Jones, 1999, 2000). In addition to the agonistic social calls comprising two or more components that we studied, both species emitted structurally different single-component calls (D. Russo, pers. obs.), and we excluded these from our analysis. To avoid pseudo-replication (Hurlbert, 1984), we selected only one call per site.

We recorded ultrasound at a high sampling rate $(350 \mathrm{kHz})$ with the real-time mode of a D1000X bat detector (Pettersson Elektronik AB, Uppsala, Sweden). This device is equipped with a built-in 16-bit recording system and stores sound as WAV files onto a Compact Flash card. When a bat pass - a series of clicks heard in frequency division as a bat flew within range (Fenton, 1970) - was detected, we triggered the recording device manually. Analysis was performed with the software BATSound ver. 3.31 (Pettersson Elektronik AB).

We chose random calls for analysis, but discarded those with a poor signal-to-noise ratio. For each call, we generated a spectrogram and an oscillogram; a power spectrum was also obtained for each call component. Spectrograms and power spectra were obtained by applying a Fast Fourier Transform (FFT) with a Hamming window (window size 1048 samples, 98\% overlap, frequency resolution $488 \mathrm{~Hz}$ ). To ensure consistency in spectrogram measurements, we selected the same threshold (17) in the BATSound settings. For each social call, we considered the following variables: number of components in the call ( $n$ comps); maximum (fmax) and minimum ( $f$ min) frequencies taken from the fundamental component (social calls are typically multi-harmonic); mean frequency of maximum energy (freq), calculated as the mean value of frequencies of highest energy taken from all call components; total call duration (totdur); and mean inter-component interval (ici), the average time interval between consecutive call components (Russo \& Jones, 1999; Pfalzer \& Kusch, 2003). For each echolocation call, we measured the start frequency, end frequency, frequency of maximum energy, and duration (Russo \& Jones, 2002). Time variables (expressed in ms) were taken from oscillograms, and frequency variables (in $\mathrm{kHz}$ ) from spectrograms, except for the frequency of maximum energy, which was measured from power spectra.

Differences in echolocation call frequencies may reflect different body size across species (Jones, 1999). Therefore, we also compared forearm length between 36 individuals of P. maderensis (15 females, 21 males) from Madeira, and 40 of P. kuhlii (20 males, 20 females) from Italy. Bats were captured in mistnets set at foraging sites, and forearm length was measured to the nearest $0.1 \mathrm{~mm}$ using dial calipers.

\section{Testing social call function and interspecific reaction to signals}

We tested whether foraging individuals of $P$. maderensis react to playbacks of $P$. kuhlii social calls on Madeira, and vice versa at the study sites in Italy. We also broadcast pre-recorded social calls of P. kuhlii at foraging sites of this species to compare heterospecific and conspecific reactions. Twelve sites (all near street lamps) were selected in each geographical area. A 'response' to social calls was represented by a difference in activity - measured as the number of bat passes during 3-min playback sessions - between experimental trials (social call playback) and 'control' (playback of recordings of background noise). The food patch defence hypothesis (Barlow \& Jones, 1997b) was verified when activity (number of bat passes of target species) measured during experimental trials was lower than that during playback of control sound.

Experimental trial sequences were generated following Barlow \& Jones (1997b). In the BATSound software, we applied the functions 'copy' and 'paste' to create sequences of social calls (previously recorded in the field in real time with a D-1000X bat detector) within a blank sound (WAV) file. Social calls, arranged in pairs, were repeated every $10 \mathrm{~s}$ in 3-min sequences. Control sequences contained only background noise. In this way we generated 36 sequences -12 with P. kuhlii calls, 12 with P. maderensis, and 12 control files. Sound was played back by connecting the D1000X to an L60 
ultrasound loudspeaker (Pettersson Elektronik AB); the maximum sound pressure level of signals broadcast by the device is c. $95 \mathrm{~dB}$ at $1 \mathrm{~m}$ (L. Pettersson, pers. comm.). The intensity of playback sequences was calibrated by detecting the sound broadcast with a U30 bat detector (Ultra Sound Advice, London, UK) at a distance of 15-20 m (i.e. approximately equal to the distance between the loudspeaker and bats in the field). Signals heard on the bat detector that were of a similar loudness to calls emitted by bats in flight at a comparable distance were used in the experiment. When needed, the sound pressure level was adjusted with the 'edit volume' option in the BATSound software. All sequences used for experiments had similar sound pressure levels.

The identity of bats under investigation at the experimental sites was confirmed by examining time-expanded or real-time recordings taken from foraging bats immediately before and after (and, in many cases, during) the experiment (for the criteria applied to identify P. kuhlii see Russo \& Jones, 1999, 2002). All selected sites were well-known foraging areas of the two species under investigation, so there was no risk of accidentally counting passes by species other than those of interest. The number of passes was counted with a bat detector (D240; Pettersson Elektronik AB, U30; Ultra Sound Advice) in the heterodyne mode set to 45 and $40 \mathrm{kHz}$ on Madeira and in Italy, respectively, corresponding to peak frequencies of the echolocation calls emitted by the study species (Russo \& Jones, 1999, 2002; S. Teixeira \& D. Russo, pers. obs.). Because sites were illuminated by street lights, bats were often observed during foraging, and their silhouette and flight style could be determined.

Activity was measured by counting the number of passes at each foraging site during playback sessions. The loudspeaker was positioned at a height of c. $2.5 \mathrm{~m}$ and directed upwards. We randomized both the order in which sites were visited and the sequence (social calls or control) broadcast. At all sites, a silent period of $3 \mathrm{~min}$ was used between tests to minimize any potential carry-over effects from the previous treatment.

\section{Statistical analysis}

We used an ANOVA to carry out univariate comparisons between species for all call variables. Most variables showed a normal distribution of residuals, as ascertained by a RyanJoiner test of normality $(P>0.05)$, and variance homogeneity. When departure from normality occurred, data were lognormalized before applying the ANOVA. Following Barlow \& Jones (1997a) and Russo \& Jones (2000), we also tested whether continuous call variables allowed for a multivariate discrimination between species. We applied a quadratic discriminant function analysis (DFA) with cross-validation including variables fmax, fmin, freq, totdur and ici. We generated Wilk's $\lambda$ values with a MANOVA to test for statistical significance of the DFA model and to assess the discrimination power of each variable (Parsons \& Jones, 2000; Russo \& Jones, 2002). Forearm lengths were compared between species using a general linear model ANOVA with species and gender as main factors.

The numbers of passes by bats recorded respectively during playback of social calls and control sequences broadcast at each site were compared with a sign-test (Barlow \& Jones, 1997b; Dytham, 1999). All tests were carried out with Minitab release 13 (Minitab Inc., State College, PA, USA). Statistical significance was set at $P=0.05$.

\section{RESULTS}

Social calls had a very similar structure between species (Fig. 1). In both species, calls most frequently consisted of three components. Calls selected for analysis had two to five components. One P. maderensis call (outside the random sample used for quantitative analysis) consisted of six components. We found no significant differences between species for all temporal and spectral variables except fmin, which was slightly (on average less than $1 \mathrm{kHz}$ ) higher in P. maderensis (Table 1). For this factor too, frequency ranges largely overlapped between species.

DFA corroborated these results because limited discrimination was achieved. The best discriminating model included all variables, and although it correctly classified $80 \%$ of $P$. kuhlii calls (i.e. 40 out of 50 ), it did so for only $58 \%$ (29 out of 50) of P. maderensis calls, providing an overall discrimination performance of $69 \%$. This was only $19 \%$ higher than random classification (50\%). The model was significant (MANOVA, Wilk's $\lambda=0.799, P<0.002$ ). Wilk's $\lambda$ values were identical (1.00) for all factors except fmin, which showed a slightly smaller value (0.83), corresponding to a better discrimination performance. When fmin was removed from the DFA, classification performance dropped to only $60 \%$ (i.e. only $10 \%$ above random classification).

Unlike social calls, echolocation calls differed markedly between species (Table 1). No overlap occurred between end frequency or frequency of maximum energy between species. Start frequency showed a borderline $(P=0.07)$, non-signifi-

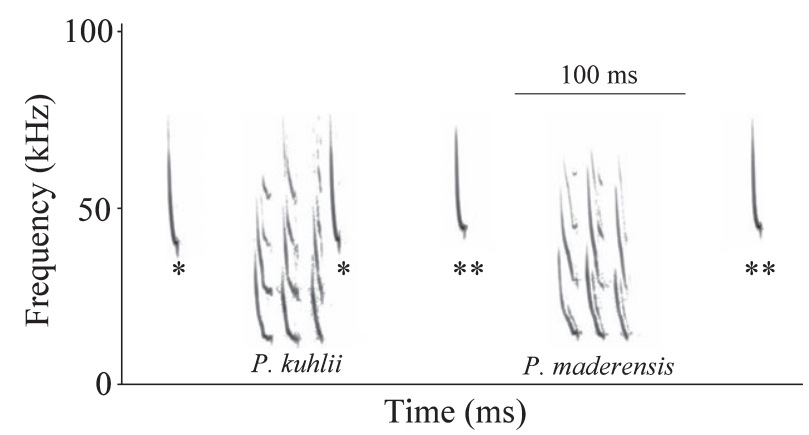

Figure 1 Spectrograms of three-component social calls of Pipistrellus kuhlii and Pipistrellus maderensis and corresponding echolocation pulses (marked with asterisks: ${ }^{\star}$ denotes P. kuhlii; ** denotes $P$. maderensis). 
Table 1 Descriptive statistics for parameters of Pipistrellus maderensis and Pipistrellus kuhlii social and echolocation calls ( $n=50$ for each species) and ANOVA levels of significance for differences between species.

\begin{tabular}{|c|c|c|c|}
\hline Parameter & P. maderensis & P. kuhlii & $P$ \\
\hline \multicolumn{4}{|l|}{ Social calls } \\
\hline$n$ comps & $\begin{array}{l}3.1 \pm 0.8 \\
2-5\end{array}$ & $\begin{array}{l}3.1 \pm 0.8 \\
2-5\end{array}$ & n.s. \\
\hline fmin $(\mathrm{kHz})$ & $\begin{array}{l}12.0 \pm 0.9 \\
10.2-13.6\end{array}$ & $\begin{array}{c}11.3 \pm 0.6 \\
9.5-13.6\end{array}$ & $<0.001$ \\
\hline$f \max (\mathrm{kHz})$ & $\begin{array}{l}38.7 \pm 8.5 \\
26.6-70.8\end{array}$ & $\begin{array}{l}40.0 \pm 8.8 \\
25.2-63.2\end{array}$ & n.s. \\
\hline freq $(\mathrm{kHz})$ & $\begin{array}{l}17.8 \pm 2.9 \\
14.9-28.9\end{array}$ & $\begin{array}{l}17.6 \pm 3.9^{*} \\
12.9-29.0\end{array}$ & n.s. \\
\hline totdur (ms) & $\begin{array}{l}37.1 \pm 8.7 \\
21-57\end{array}$ & $\begin{array}{l}37.0 \pm 7.4^{*} \\
21-58\end{array}$ & n.s. \\
\hline$i c i(\mathrm{~ms})$ & $\begin{array}{c}14.9 \pm 2.8 \\
9.7-23.0\end{array}$ & $\begin{array}{l}14.7 \pm 2.9 \\
10.0-21.0\end{array}$ & n.s. \\
\hline \multicolumn{4}{|l|}{ Echolocation calls } \\
\hline Start frequency $(\mathrm{kHz})$ & $\begin{array}{l}65.8 \pm 10.9 \\
45.7-95.3\end{array}$ & $\begin{array}{l}62.1 \pm 8.9 \\
44.3-82.4\end{array}$ & n.s. \\
\hline End frequency $(\mathrm{kHz})$ & $\begin{array}{l}44.8 \pm 1.2 \\
42.2-47.7\end{array}$ & $\begin{array}{l}38.7 \pm 1.3 \\
35.4-41.5\end{array}$ & $\dagger$ \\
\hline $\begin{array}{l}\text { Frequency of maximum } \\
\text { energy }(\mathrm{kHz})\end{array}$ & $\begin{array}{l}47.0 \pm 2.0 \\
43.7-54.9\end{array}$ & $\begin{array}{l}40.7 \pm 1.2 \\
36.5-42.4\end{array}$ & $\dagger$ \\
\hline Duration (ms) & $\begin{array}{l}5.2 \pm 1.0 \\
3.4-8.1\end{array}$ & $\begin{array}{c}6.2 \pm 1.0^{*} \\
4.8-9.5\end{array}$ & $<0.001$ \\
\hline
\end{tabular}

$n$ comps, number of social call components; fmin, minimum frequency; fmax, maximum frequency; freq, frequency of maximum energy; totdur, total call duration; ici, mean time interval between call components; n.s., not significant.

${ }^{*}$ ANOVA carried out on log-transformed values.

$\dagger$ Parameters showing no range overlap between species were not tested with ANOVA. Values shown are means \pm SDs, and ranges are also presented.

cant trend towards higher values in P. maderensis, and duration was significantly shorter for the latter.

The higher frequencies used in echolocation by $P$. maderensis are paralleled by its smaller size. Both gender $\left(F_{1,1,72}=15.56\right)$ and species $\left(F_{1,1,72}=17.19\right)$ had significant effects on forearm length $(P<0.005)$, whereas the interaction between them did not. In $P$. maderensis, males had forearm lengths averaging $32.7 \mathrm{~mm}(0.9 \mathrm{~mm} \mathrm{SD})$, and females averaged $33.3 \mathrm{~mm}$ (0.7). In P. kuhlii, males had forearm

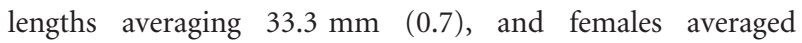
$34.2 \mathrm{~mm}$ (1.0).

In all playback tests except one (on P. maderensis), social calls induced a significantly reduced bat activity relative to control sequences (Fig. 2). Pipistrellus kuhlii showed similar responses both to its own recordings (sign test, $n=12$, median $=-7.5, P<0.001)$ and to those of $P$. maderensis $(n=12$, median $=-12.0, P<0.001)$. Likewise, $P$. maderensis showed a significant decrease in activity when $P$. kuhlii social calls were broadcast $(n=12, \quad$ median $=-4.5$, $P<0.01)$.

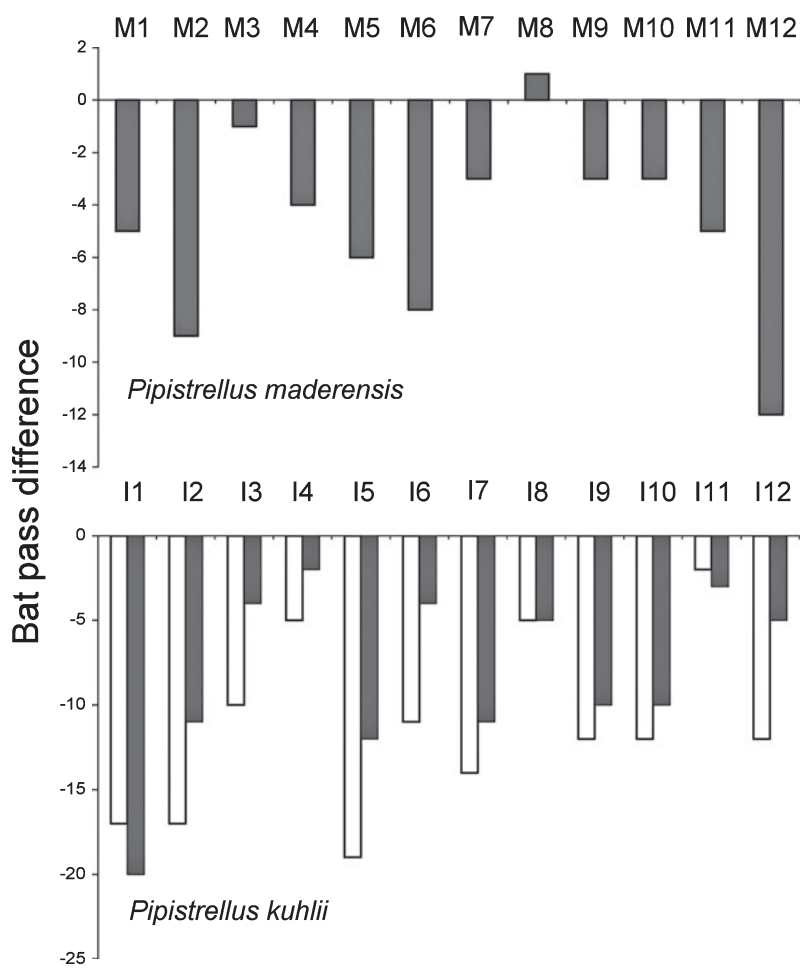

Figure 2 The response of Pipistrellus maderensis and P. kuhlii to playback experiments at 24 foraging sites (12 on Madeira, 12 in Italy). Each bar represents the difference in bat activity, measured as the difference in the number of bat passes between experimental trials and control trials for one site. Grey bars illustrate responses to $P$. kuhlii calls, and white bars illustrate responses to P. maderensis calls. M 1-12: sites on Madeira. I 1-12: sites in Italy.

\section{DISCUSSION}

\section{Social and echolocation calls in $P$. maderensis and $P$. kuhlii}

Our study demonstrated a strong similarity of social call structure in the two bat species. Although fmin showed a statistically detectable difference between the species and was the main contributor to the multivariate discrimination of P. kuhlii (but not of P. maderensis) social calls, this variable showed considerable overlap between taxa, suggesting that the observed difference is of little biological significance. Moreover, the number of call components showed no consistent differences between species, unlike the situation in sympatric $P$. pipistrellus and P. pygmaeus, which typically show differences in the numbers of components, frequency values, and even in the spectrogram 'shape' of the call components (Barlow \& Jones, 1997a).

Although the number of call components also showed an identical modal value in both species (three), calls with a different number of components were sometimes recorded. As in a previous study (Russo \& Jones, 1999), the maximum number of components recorded for $P$. kuhlii in this study was five. Six components can occur in P. maderensis, albeit very 
rarely. Further playback experiments would be needed to ascertain the role of the single-component calls recorded from both pipistrelle bat species at foraging sites.

The functional value of the different number of components is debatable. In both species, the same bat may consecutively emit calls with different numbers of components (D. Russo, pers. obs.), thus ruling out the hypothesis that this variable conveys 'stable' information regarding the emitter with respect to gender, age, rank or body size. Varying the number of components in the calls may instead offer a simple, unambiguous way to express some aspect of motivation in the signaller (e.g. it might correspond to a more or less 'intense' message during chases).

Given the similarity in the social calls, we predicted that each species would respond to social calls emitted by the other species. This was confirmed by the reactions recorded in our experiments; that is, social calls were so similar between species that they overcame species communication barriers, and each species responded to the social calls of the other. This result differs from that in the cryptic species $P$. pipistrellus and P. pygmaeus, where responses are species-specific (Barlow \& Jones, 1997b).

Although social calls have retained the same structure (and function) as in P. kuhlii, echolocation calls in P. maderensis showed major structural differences, with frequency of maximum energy and end frequency being markedly higher in $P$. maderensis, which also exhibited a significantly if only slightly (c. $1 \mathrm{~ms}$ ) shorter call duration. The only parameter that did not differ significantly between species (start frequency) still showed a trend towards higher values in P. maderensis. Start frequency is affected substantially by atmospheric attenuation (Lawrence \& Simmons, 1982), and is hence strongly dependent upon the distance that the bat was recorded at. Start frequency therefore shows considerable variability within species, which makes the detection of interspecific differences difficult. Moreover, P. maderensis had a slightly, yet significantly, smaller body size than P. kuhlii. We propose that the observed differences in echolocation call frequencies arise from the smaller body size of $P$. maderensis, which gives it a narrower vocal tract, causing the production of higher frequencies (Heller \& Helversen, 1989; Jones, 1999). Call duration also typically scales negatively with body mass across species that emit calls containing narrowband components (Jones, 1999). Body size reduction is a widespread effect of insularity reported for many bat species, and is probably related to limited food resources (Krzanowski, 1967). Correlated evolution between morphological (e.g. body mass, bill size) and acoustic (i.e. song frequency and temporal patterning) traits has also been proposed for some bird groups (Podos, 2000; Seddon, 2004).

An alternative hypothesis is that higher frequencies allow P. maderensis to exploit prey of different size, as by adopting higher call frequencies a bat may detect smaller prey. The wavelength of sound gives an estimate of prey size below which echo strength rapidly decreases (Houston et al., 2004). Wave- length (in mm) may be calculated as $1000 \times$ (speed of sound in air at $25^{\circ} \mathrm{C}$ and $80 \%$ relative humidity, equalling $347.65 \mathrm{~m} \mathrm{~s}^{-1}$ ) per call frequency of maximum energy $(\mathrm{Hz})$. Using the mean values recorded in this study, we obtain wavelength values of 7.4 and $8.5 \mathrm{~mm}$ for P. maderensis and P. kuhlii, respectively, values that might allow $P$. maderensis to better detect smaller prey.

\section{A case of stabilizing selection?}

In species-rich assemblages, similarity in social calls may result in ambiguous communication and, consequently, in decreased fitness. This situation may prompt acoustic character displacement, resulting in different call structures and distinct communication channels between species. In rhinolophoid bats, the constant frequency component of echolocation pulses may convey social information such as species identity (Kingston et al., 2001; Thabah et al., 2006; Russo et al., 2007). This hypothesis may explain the divergence in echolocation call frequencies recently reported for Sardinian populations of Rhinolophus hipposideros and R. euryale, which do not overlap with those for R. mehelyi (Russo et al., 2007). In that case, geographic isolation prevents gene flow from allopatric, mainland populations, which would otherwise mask the observed pattern.

Pressures leading to social call divergence are also evident in the sympatric pipistrelles $P$. pipistrellus and P. pygmaeus (Barlow \& Jones, 1997a; Russo \& Jones, 2000). Such differences are effective in allowing unambiguous communication with conspecifics and may have evolved partly by acoustic character displacement (Barlow \& Jones, 1997b; Jones, 1997). Both P. pipistrellus and P. pygmaeus emit social calls that are more distinctive than in the species we studied: this may reflect both a longer time since they diverged from a common ancestor (possibly c. $5 \mathrm{Ma}$; Barratt et al., 1997) and their frequent occurrence in sympatry (Mayer \& von Helversen, 2001).

In a simplified bat community such as that of Madeira, selective pressures for structural shifts such as those imposed by the presence of species broadcasting similar signals will be absent, and stabilizing selection instead appears the most parsimonious hypothesis to explain structural and functional preservation of social calls. Although the outcome of character stabilization should be an increase in individual fitness, experimental assessments that estimate fitness are unlikely to be feasible, and hence the only conceivable approach to understanding the consequences of signal stability is that of comparative structural and functional analyses, as carried out in this study.

Although produced at different rates, calls identical to those produced at foraging sites to repel conspecifics are also employed in the mating season by males of $P$. pipistrellus and P. pygmaeus to attract females (Barlow \& Jones, 1997a). In this case, evolution has been parsimonious, as the same signal structure plays a different, context-dependent communication function. It is unknown whether the same situation occurs in mating individuals of $P$. maderensis and P. kuhlii. Should this 
be the case, partner recognition would represent a further evolutionary pressure for maintaining social call structure in these bats.

No information on social call structure is available for Tenerife, where P. maderensis and P. kuhlii are sympatric according to Pestano et al. (2003). In that case, call structure may diverge as a result of selection for effective communication barriers, and studies similar to ours set in areas of sympatry would therefore be of great interest. Habitat segregation might also play a role in preserving distinct communication at foraging sites, so this aspect would be worthwhile to investigate too. However, the phylogenetic and taxonomic status of the Canarian P. kuhlii appears uncertain, and bats on the Canary Islands may be quite distinct from those of mainland populations: this should be taken into account for future behavioural and bioacoustical comparisons. On the Canary Islands, P. maderensis and P. kuhlii show pronounced morphological similarities. Pestano et al. (2003) found that the Canarian P. maderensis is more closely related to the local P. kuhlii clade than the latter is to P. kuhlii from continental populations. Pestano et al. (2003) suggest that the two lineages may interbreed, and hence their status as separate species is questionable. Finally, Simmons (2005) reports that Canary Island populations referred to as P. kuhlii by Pestano et al. (2003) may in fact consist of the African Pipistrellus hesperidus.

Bats may easily cross short stretches of sea: Miniopterus schreibersii and Myotis capaccinii can move between the islands of Mallorca and Menorca, a distance of at least $40 \mathrm{~km}$ (Amengual et al., 2007). It is unknown whether gene flow exists among insular populations of $P$. maderensis, but given the large distances among islands, gene flow will probably be extremely infrequent or absent. The geographical isolation of the Madeira Archipelago presents strong barriers to gene flow: it lies c. $650 \mathrm{~km}$ off the closest mainland (African coast), and is far enough from other islands harbouring $P$. maderensis to make frequent contact with allopatric populations very unlikely (Canary Islands, c. $450 \mathrm{~km}$; Azores, c. $850 \mathrm{~km}$ ).

\section{Inheritance of social calls: genes or memes?}

In this study we recorded rates of social call production of up to 0.8 calls s$^{-1}$, that is, almost a call per second (D. Russo, pers. obs.). Because two or more bats are typically found at sites where social calls are emitted, hundreds of such calls may be heard in a few hours at a single foraging site. Such signals are certainly among the most frequently emitted social calls in echolocating bats. We propose that this frequent use may account for the faithful inheritance of call structure across generations and, ultimately, across species.

An interesting analogy is offered by the cultural evolution of human languages. This follows trajectories analogous to those of biological evolution by natural selection (descent with modification; Pagel et al., 2007). In human language, words used frequently are less susceptible to change (Ellis, 2002). Modelling suggests that the number of times a word is used alters the rate at which new word forms arise, since fewer accidental errors occur for highly expressed words (Pagel et al., 2007). In an analogy with natural selection, this signifies that frequently used words are subject to stabilizing selection.

We have assumed that social call structure is shaped mainly by natural selection processes. The possible influence of social learning in determining at least some features of social calls in echolocating bats is actually unknown. In many birds, social learning plays a major role in structuring songs (e.g. Zeigler \& Marler, 2008; but see Seddon, 2004). Vocal learning is much rarer in mammals. For instance, alarm call structure in rodents is heritable, hybrids showing calls of intermediate structure (Nikol'skii et al., 1984; Nikol'skii \& Starikov, 1997) or signal structure resembling that of one parent more than the other (Koeppl et al., 1978).

However, evidence for vocal learning of social calls exists for only a few bat species. Female greater spear-nosed bats, Phyllostomus hastatus, form social groups that cooperate in foraging. Although they are not closely related, group mates produce similar social calls that function to signal group membership and facilitate cooperation (Wilkinson \& Boughman, 1998, 1999). Bats transferred experimentally between groups adjust call structure to match that of the group they join, confirming that vocal learning occurs in this species (Boughman, 1998). Hipposideros terasensis emits echolocation calls that are dominated by a constant frequency component and that are probably used in communication as well as in echolocation (Thabah et al., 2006; Russo et al., 2007). Bats transplanted into new social groups apparently shift this frequency value to match that of existing colony members (Hiryu et al., 2006). These experiments prove that some form of socially induced (i.e. learnt) 'tuning' mechanism is operating at least in some species, even though the physiological and behavioural bases for performing the adjustment must of course be genetically inherited. Therefore, stabilization of pipistrelle social calls might be driven by either genetic or cultural factors, or possibly by a combination of both: in all cases, the frequent use of such signals in communicating bats might have favoured the process. However, it is debatable whether cultural learning could be so persistent as to preserve signal structure over many generations, and to cope with the long time-frame and the dramatic changes of speciation.

\section{ACKNOWLEDGEMENTS}

Thanks go to Adriano Martinoli (University of Insubria) for providing P. kuhlii forearm measurements, and to Cristiano Spilinga, who provided some recordings of P. kuhlii from Umbria. Lars Pettersson kindly advised us on technical aspects of the loudspeaker used for the experiments. Mark Weir kindly revised the text. We are grateful to Şerban Procheş, Robert J. Whittaker, Vincenzo Penteriani and an anonymous reviewer for their valuable suggestions on a previous version of the manuscript. Antonello Migliozzi helped with figures. 


\section{REFERENCES}

Amengual, B., López-Roig, M. \& Serra-Cobo, J. (2007) First record of seasonal over sea migration of Miniopterus schreibersii and Myotis capaccinii between Balearic islands (Spain). Acta Chiropterologica, 9, 319-322.

Barlow, K.E. \& Jones, G. (1997a) Differences in songflight calls and social calls between two phonic types of the vespertilionid bat Pipistrellus pipistrellus. Journal of Zoology, 241, 315-324.

Barlow, K.E. \& Jones, G. (1997b) Function of pipistrelle social calls: field data and a playback experiment. Animal Behaviour, 53, 991-999.

Barratt, E.M., Deaville, R., Burland, T.M., Bruford, M.W., Jones, G., Racey, P.A. \& Wayne, R.K. (1997) DNA answers the call of pipistrelle bat species. Nature, 387, 138-139.

Berger-Tal, O., Berger-Tal, R., Korine, C., Holderied, M.W. \& Fenton, M.B. (2007) Echolocation calls produced by Kuhl's pipistrelles in different flight situations. Journal of Zoology, 274, 59-64.

Boughman, J.W. (1998) Vocal learning by greater spear-nosed bats. Proceedings of the Royal Society B: Biological Sciences, 265, 227-233.

Braune, P., Schmidt, S. \& Zimmermann, E. (2008) Acoustic divergence in the communication of cryptic species of nocturnal primates (Microcebus ssp.). BMC Biology 6, 19.

Dytham, C. (1999) Choosing and using statistics. A biologist's guide. Blackwell Science, Oxford.

Ellis, N.C. (2002) Frequency effects in language processing: a review with implications for theories of implicit and explicit language acquisition. Studies in Second Language Acquisition, 24, 143-188.

Estes, S. \& Arnold, S.A. (2007) Resolving the paradox of stasis: models with stabilizing selection explain evolutionary divergence on all timescales. The American Naturalist, 169, 227-244.

Fenton, M.B. (1970) A technique for monitoring bat activity with results obtained from different environments in southern Ontario. Canadian Journal of Zoology, 48, 847-851.

Fenton, M.B. (1977) Variation in the social calls of little brown bats (Myotis lucifugus). Canadian Journal of Zoology, 55, 1151-1156.

Fenton, M.B. (1985) Communication in the Chiroptera. Indiana University Press, Bloomington, IN.

Fenton, M.B. (2003) Eavesdropping on the echolocation and social calls of bats. Mammal Review, 33, 193-204.

Findley, J.S. (1993) Bats. A community perspective. Cambridge studies in ecology. Cambridge University Press, New York.

Gerhardt, H.C. \& Huber, F. (2002) Acoustic communication in insects and anurans: common problems and diverse solutions. The University of Chicago Press, Chicago.

Greenfield, M.D. (1997) Sexual selection and the evolution of advertisement signals. Perspectives in ethology, Vol. 12 (ed. by M.D. Beecher, D.H. Owings and N. Thompson), pp. 145-177. Plenum, New York.
Heller, K.-G. \& Helversen, O. (1989) Resource partitioning of sonar frequency bands in rhinolophoid bats. Oecologia, 80, 178-186.

Higgins, L.A. \& Waugaman, R.D. (2004) Sexual selection and variation: a multivariate approach to species-specific calls and preferences. Animal Behaviour, 68, 1139-1153.

Hiryu, S., Katsura, K., Nagato, T., Yamazaki, H., Lin, L.-L., Watanabe, Y. \& Riquimaroux, H. (2006) Intra-individual variation in the vocalized frequency of the Taiwanese leafnosed bat, Hipposideros terasensis, influenced by conspecific colony members. Journal of Comparative Physiology A, 192, 807-815.

Höbel, G. \& Gerhardt, H.C. (2003) Reproductive character displacement in the acoustic communication system of green tree frogs (Hyla cinerea). Evolution, 57, 894-904.

Honda-Sumi, E. (2005) Difference in calling song of three field crickets of the genus Teleogryllus: the role in premating isolation. Animal Behaviour, 69, 881-889.

Houston, R.D., Boonman, A.M. \& Jones, G. (2004) Do echolocation signal parameters restrict bats' choice of prey? Echolocation in bats and dolphins (ed. by J. Thomas, C. Moss and M. Vater), pp. 339-345. Chicago University Press, Chicago.

Hulva, P., Horáček, I., Strelkov, P.P. \& Benda, P. (2004) Molecular architecture of Pipistrellus pipistrellus/Pipistrellus pygmaeus complex (Chiroptera: Vespertilionidae): further cryptic species and Mediterranean origin of the divergence. Molecular Phylogenetics and Evolution, 32, 1023-1035.

Hunt, J., Blows, M.W., Zajitschek, F., Jennions, M.D. \& Brooks, R. (2007) Reconciling strong stabilizing selection with the maintenance of genetic variation in a natural population of black field crickets (Teleogryllus commodus). Genetics, 177, 875-880.

Hurlbert, S.H. (1984) Pseudoreplication and the design of ecological field experiments. Ecological Monographs, 54, 187-211.

Hutterer, R., Ivanova, T., Meyer-Cords, C. \& Rodrigues, L. (2005) Bat migrations in Europe. A review of banding data and literature. German Federal Agency for Nature Conservation, Bonn.

Irwin, D.E., Bensch, S. \& Price, T.D. (2001) Speciation in a ring. Nature, 409, 333-337.

Jesus, J., Teixeira, S., Teixeira, D., Freitas, T. \& Russo, D. (in press) Vertebrados terrestres autóctones dos Arquipélagos da Madeira e Selvagens. Répteis e Mamíferos. Biodiversidade madeirense: avaliação e conservação. Direcção Regional de Ambiente. Secretaria Regional do Ambiente, Funchal, Portugal.

Jones, G. (1997) Acoustic signals and speciation: the roles of natural and sexual selection in the evolution of cryptic species. Advances in the Study of Behavior, 26, 317354.

Jones, G. (1999) Scaling of echolocation call parameters in bats. Journal of Experimental Biology, 202, 3359-3367.

Kingston, T., Lara, M.C., Jones, G., Akbar, Z., Kunz, T.H. \& Schneider, C.J. (2001) Acoustic divergence in two cryptic 
Hipposideros species: a role for social selection? Proceedings of the Royal Society B: Biological Sciences, 268, 1381-1386.

Koeppl, J.W., Hoffmann, R.S. \& Nadler, C.F. (1978) Pattern analysis of acoustical behavior in four species of ground squirrels. Journal of Mammalogy, 59, 677-696.

de Kort, S.R., den Hartog, P.M. \& ten Cate, C. (2002) Vocal signals, isolation and hybridization in the vinaceous dove (Streptopelia vinacea) and the ring-necked dove (S. capricola). Behavioral Ecology and Sociobiology, 51, 378-385.

Krzanowski, A. (1967) The magnitude of islands and the size of bats (Chiroptera). Acta Zoologica Cracoviensia, 12, 281-346.

Lawrence, B.D. \& Simmons, J.A. (1982) Measurements of atmospheric attenuation at ultrasonic frequencies and the significance for echolocation by bats. Journal of the Acoustical Society of America, 71, 585-590.

Lomolino, M.V. (2005) Body size evolution in insular vertebrates: generality of the island rule. Journal of Biogeography, 32, 1683-1699.

Mayer, F. \& von Helversen, O. (2001) Sympatric distribution of two cryptic bat species across Europe. Biological Journal of the Linnean Society, 74, 365-374.

Mayr, E. (1967) The challenge of island faunas. Australian Natural History, 15, 369-374.

Millien, V. (2006) Morphological evolution is accelerated among island mammals. PLoS Biology, 4, e321, doi: 10.1371/ journal.pbio.0040321.

Nikol'skii, A.A. \& Starikov, V.P. (1997) Variation in the alarm call in ground squirrels Spermophilus major and S. erythrogenys (Rodentia, Sciuridae) in the contact zone in the Kurgan Oblast. Russian Journal of Zoology, 1, 340-351.

Nikol'skii, A.A., Denisov, V.P., Stojko, T.G. \& Formosov, N.A. (1984) The alarm call in F1 hybrids Citellus pygmaeus x C. suslica (Sciuridae, Rodentia). Zoologicheskii Zhurnal, 63, 1216-1225.

Obrist, M. (1995) Flexible bat echolocation: the influence of individual, habitat and conspecifics on sonar signal design. Behavioral Ecology and Sociobiology, 36, 207-219.

Pagel, M., Atkinson, Q.D. \& Meade, A. (2007) Frequency of word-use predicts rates of lexical evolution throughout Indo-European history. Nature, 449, 717-721.

Parsons, S. \& Jones, G. (2000) Acoustic identification of twelve species of echolocating bat by discriminant function analysis and artificial neural networks. Journal of Experimental Biology, 203, 2641-2656.

Paterson, H.E.H. (1985) The recognition concept of species. Species and speciation (ed. by E. Vrba), pp. 21-29. Transvaal Museum Monograph 4, Pretoria, South Africa.

Pestano, J., Brown, R.P., Suarez, N.M. \& Fajardo, S. (2003) Phylogeography of pipistrelle-like bats within the Canary Islands, based on mtDNA sequences. Molecular Phylogenetics and Evolution, 26, 55-63.

Pfalzer, G. \& Kusch, J. (2003) Structure and variability of bat social calls: implications for specificity and individual recognition. Journal of Zoology, 261, 21-33.

Podos, J. (2000) Correlated evolution of morphology and vocal signal structure in Darwin's finches. Nature, 409, 185-188.
Pröhl, H., Koshi, R.A., Mueller, U., Rand, S. \& Ryan, M.J. (2006) Geographic variation of genetic and behavioural traits in northern and southern túngara frogs. Evolution, 60, 1669-1679.

Rainho, A., Marques, J.T. \& Palmeirim, J.M. (2002) Os morcegos dos arquipélagos dos Açores e da Madeira: um contributo para a sua conservação. Centro de Biologia Ambiental/Instituto de Conservação de Natureza, Lisbon.

Ritchie, M.G. (1996) The shape of female mating preferences. Proceedings of the National Academy of Sciences USA, 93, 14628-14631.

Russ, G.M., Racey, P.A. \& Jones, G. (1998) Intraspecific responses to distress calls of the pipistrelle bat, Pipistrellus pipistrellus. Animal Behaviour, 55, 705-713.

Russo, D. \& Jones, G. (1999) The social calls of Kuhl's pipistrelles Pipistrellus kuhlii (Kuhl, 1819): structure and variation (Chiroptera: Vespertilionidae). Journal of Zoology, London, 249, 476-481.

Russo, D. \& Jones, G. (2000) The two cryptic species of Pipistrellus pipistrellus (Chiroptera: Vespertilionidae) occur in Italy: evidence from echolocation and social calls. Mammalia, 64, 187-197.

Russo, D. \& Jones, G. (2002) Identification of twenty-two bat species (Mammalia: Chiroptera) from Italy by analysis of time-expanded recordings of echolocation calls. Journal of Zoology, 258, 91-103.

Russo, D., Mucedda, M., Bello, M., Biscardi, S., Pidinchedda, E. \& Jones, G. (2007) Divergent echolocation call frequencies in insular rhinolophids (Chiroptera): a case of character displacement? Journal of Biogeography, 34, 2129-2138.

Ryan, M.J. \& Rand, A.S. (1993) Species recognition and sexual selection as a unitary problem in animal communication. Evolution, 47, 647-657.

Seddon, N. (2004) Ecological adaptation and species recognition drives vocal evolution in neotropical suboscine birds. Evolution, 59, 200-215.

Simmons, N.B. (2005) Order Chiroptera. Mammal species of the world: a taxonomic and geographic reference, Vol. 1, 3rd edn. (ed. by D.E. Wilson and D.M. Reeder), pp. 312-529. Johns Hopkins University Press, Baltimore, MD.

Stearns, S.C. \& Hoekstra, R.F. (2005) Evolution: an introduction. Oxford University Press, Oxford.

Thabah, A., Rossiter, S.J., Kingston, T., Zhang, S., Parsons, S., Mya, K.M., Zubaid, A. \& Jones, G. (2006) Genetic divergence and echolocation call frequency in cryptic species of Hipposideros larvatus s.l. (Chiroptera: Hipposideridae) from the Indo-Malayan region. Biological Journal of the Linnean Society, 88, 119-130.

Vaughan, N., Jones, G. \& Harris, S. (1997) Identification of British bat species by multivariate analysis of echolocation call parameters. Bioacoustics, 7, 189-207.

Vernier, E. \& Bogdanowicz, W. (1999) Pipistrellus kuhlii. The atlas of European mammals (ed. by A.J. Mitchell-Jones, G. Amori, W. Bogdanowicz, B. Kryštufek, P.J.H. Reijnders, F. Spitzenberger, M. Stubbe, J.B.M. Thissen, V. Vohralík and J. Zima), pp. 120-121. Academic Press, London. 
Wilkinson, G.S. \& Boughman, J.W. (1998) Social calls coordinate foraging in greater spear-nosed bats. Animal Behaviour, 55, 337-350.

Wilkinson, G.S. \& Boughman, J.W. (1999) Social influences on foraging in bats. Mammalian social learning: comparative and ecological perspectives (ed. by H.O. Box and K. Gibson), pp. 188-204. Symposia of the Zoological Society of London, 73. Cambridge University Press, Cambridge.

Zeigler, H.P. \& Marler, P. (2008) Neuroscience of bird song. Cambridge University Press, Cambridge.

\section{BIOSKETCH}

Danilo Russo teaches Conservation Biology and Management of Nature Reserves at the Faculty of Agriculture, University of Naples Federico II. His main research work focuses on bat ecology, echolocation and conservation biology.

Editor: Şerban Procheş 